\title{
24tgencine ל̇etimmungen.
}

1. Die Gemeinde hat fin formohl bei der Dor = wie all bei der Shlluķliturgie (nid̨̧ etwa nur bei der Sḑriftlejung) zul erḩeben und während der ganjen Dauer derjelben jtę̧en ju bleiben.

2. Die Gemeinde hat fin fingend an der Eiturgie $\mathfrak{z u}$ beteiligen.

3. Die Bejange der Gemeinde gefdiehen unter Begleitung der Orgel oder der Militär. mufit. Uln hohen fefttagen wird, wo es geht, der Gemeindegejang auker burd die Orgel dur Pofaunen, Trompeten und Paufen begleitet.

4. Der Kirdhendhor, welder in allen 2rili. tảrgemeinden, in denen befondere Mrititärgottes: dienfte gehalten werden, zu bilden ift, hat fowohl die führung des Gemeindegejanges ju über. nehmen, als auh a capella an ben für ihn bejtimmten Stellen gute firḑlið̧e Kompofitionen biblijđer oder anderer der feier entipreḑender Certe vorjutragen. 


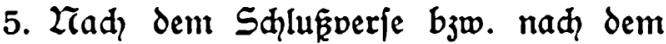
Umen hinter dem Segen hat der Orgarift unmittelbar abjufezzen, um der Gemeinde Raum für das ftille Gebet ju laffen. Erift nad einer angemeffenen Gebetspauje fetzt er mit dem Zladipiel ein. 